1980

\title{
Personality correlates of musical talent
}

Walter W. Tunstall

Follow this and additional works at: https://scholarscompass.vcu.edu/etd

Part of the Psychology Commons

(C) The Author

\section{Downloaded from}

https://scholarscompass.vcu.edu/etd/5624

This Thesis is brought to you for free and open access by the Graduate School at VCU Scholars Compass. It has been accepted for inclusion in Theses and Dissertations by an authorized administrator of VCU Scholars Compass.

For more information, please contact libcompass@vcu.edu. 


\section{SCHOOL OF ARTS AND SCIENCES}

VIRGINIA COMMONWEALTH UNIVERSITY

This is to certify that the thesis prepared by Walter W. Tunstall entitled Personality Correlates of Musical Talent has been approved by $h$ is committee as satisfactory completion of the thes is requirement for the Master of Science degree in Psychology.

Cha irman:

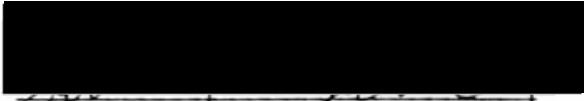

Associate Professor of Psychology

Members:

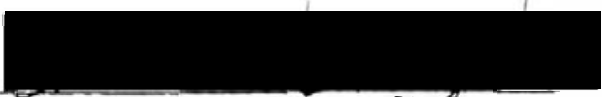

Thomas H. Leaney, Ph.D.

Associate Professor of Psychology

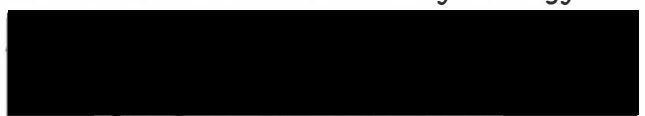

Donelson Forsyth, Ph.D.

Assistant Professor of Psychology

Dr. William A. Glynn,

Acting Dean, School of Arts \& Sciences

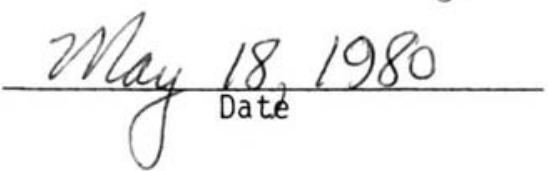

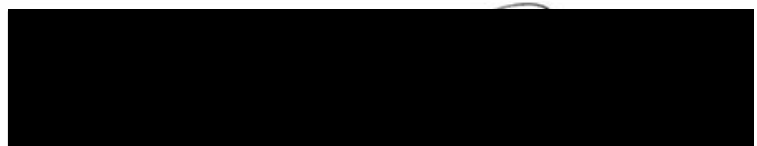

William S. Ray, Ph.D.

Chairman, Department of Psyghology 
PERSONALITY CORRELATES OF MUSICAL TALENT

A thesis submitted in partial fulfillment of the requirements for the degree of Master of Science at Virginia Commonwealth University

by

Walter W. Tunstall

Director: Dr. John M. Mahoney

Associate Professor of Psychology

Richmond, Virginia

May, 1980 


\section{ACKNOWLEDGEMENTS}

I would like to express my sincere gratitude and thanks to Dr. John M. Mahoney for his exemplary advisory assistance as thes is director, and to Dr. Thomas H. Leahey and Dr. Donelson R. Forsyth for their valuable suggestions and recommendations as thesis committee members.

I also wish to express my sincere appreciation to Mr. Ronald Thomas, Chairman of the Music Department at Virginia Commonwealth University, and Dr. Homer Rudolf, Chairman of the Music Department at the University of Richmond for their gracious assistance in the realization of this research project.

Finally, I would like to thank the study's participants, the talented and not so talented, who helpfully took time from burgeoning schedules to provide us insight into their personal worlds. 
List of Tables.................. . . i i i

List of figures .................. . . vi

Abstract .................... v

Introduction . . . . . . . . . . . . . . . . . 1

Aptitude and Talent .................... 2

The Elemental Viewpoint or Theory of Specifics . . . . . . 4

A Behavioral View ................. 8

Omnibus Theory.................... . . . 8

The Nature of Talent . . . . . . . . . . . . . . . . 9

Variants of Musical Talent . . . . . . . . . . . 11

Premature Emergency of Musical Talent . . . . . . . . 12

Inheritance of Musical Capacities . . . . . . . . . . 13

The Measurement of Musical Behavior . . . . . . . . . 17

The Seashore Measures of Musical Talents . . . . . . . 18

The Psychological Theory of the Seashore Tests . . . . . 20

The Schoen Battery . . . . . . . . . . . . . . . 21

The Kwalwasser-Dykema Tests . . . . . . . . . 22

The Ortmann Battery ........... . . . 23

The Iowa Tests of Musical Literacy . . . . . . . . 23

The Validity of the Seashore Tests . . . . . . . . 23

Studies of the Schoen, Kwalwasser-Dykema and
Ortmann Batteries 
The Analysis of Musical Talent Through Statistical

Techniques................. . 28

The Nature of Talent . . . . . . . . . . . . . 29

The Psychology of Music and Art . . . . . . . . . . . 30

The Interrelation of Musical Talent and Personality . . . . 33

Intoversion/Extroversion ................ 34

Hypothesis........................ . 39

Method .......................... 40

1. Subjects...................... 40

2. Materials .................... 41

3. Procedure .................... 41

Results....................... 43

Factor Analysis .. . . . . . . . . . . . . . . 43

Analys is of Variance.................. . . 43

Pearson Product Moment Correlation. . . . . . . . . . 43

Table 1. ....................... . . . 45

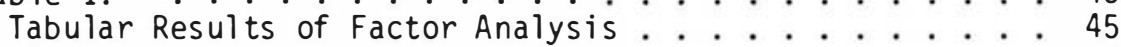

Table 2. ...................... . . 46

Correlations Between Talent and the 16PF Pearson

Product Moment Correlation ............ 46

Discussion...................... . . 47

Figure 1. . . . . . . . . . . . . . . . . . . 49

List of References.............. . . 54-56

Appendix 1. ..................... 57

Vita....................... 58 


\section{LIST OF TABLES}

Table

1. Tabular Results of Factor Analysis . . . . . . . . . . . 42

2. Correlations Between Talent and the 16PF . . . . . . . . 43 (Pearson Product Moment Correlation) 
LIST OF FIGURES

Figure

Page

1. Graphic Representation of Personality Profiles . . . . . 49

Low Talent Pre-professional High Talent 


\section{ABSTRACT}

PERSONALITY CORRELATES OF MUSICAL TALENT

Walter W. Tunstall

Virginia Commonwealth University, 1980

Major Director: Dr. John M. Mahoney

Existing commentary and research on the nature of musical talent was reviewed and found lacking in conception, primarily because previous researchers had failed to identify the unique creative element a musician contributes to a musical performance. The personality structures of 60 subjects, 32 males and 28 females, were analyzed via the 16PF. A Pearson Product Moment Correlation, an ANOVA, and a second order factor analysis were used to assess the relationship between personality and musical talent for 1) persons with little or no musical ability, 2) highly talented university music majors, and 3) professional performing musicians. Significant relationships were found for talent and perseverance, age, self-sufficiency, dicipline, and creativity. Non-significant linear trends were found for nine other personality dimensions. Personality profiles were constructed for the three groups. 


\section{INTRODUCTION}

Throughout recorded history, deference has been shown to those individuals who, for want of a better term, may be roughly categorized as artists. This will not strike any of us as remarkable, since each of us has probably felt a similar deference for the artist. Referants such as "divine," "traveling to the beat of a different drum," and "genius" suggest the widespread recognition of the different and special ability possessed by the artist. History and contemporary life abound with accounts of the extraordinary lives and accomplishments of artists. The question naturally arises, then, how is the artist different from the non-artist?

An obvious answer to this question is that the artist possesses talent, whereas the non-artist does not. This answer, however, is less than satisfying since it provides no specific account of "talent." It abandons the matter at a level of generality that provides no meaningful insight into the nature of the differences between the artist and non-artist. What is to be preferred is a discrete specification of the components summarily referred to as talent, or in lieu of that, specific correlates of talent. The present study addresses itself to that end.

The present study will restrict the scope of its inquiry so that a more detailed view of one kind of artistic endeavor may be had. Rather than attempt to show how all artists differ from non-artists, the present study will look at one subgroup of artists - the performing musician. To rephrase the original question, then, this study will investigate how musically talented people differ from those who are not. 


\section{APTITUDE AND TALENT}

Each of us has probably heard a musical performance of one of our favorite pieces which was more or less satisfying. It just sounded good or bad. If one took the time to reflect upon why one performance "sounded better" than another, he or she probably concluded that the difference was due to the musical ability or talent of the performer.

Recent opinions regarding the nature of musical talent, ability, and aptitude are by no means unanimous. Révész (1954) contends that a sharp distinction must be maintained between musical aptitude and musical talent. By aptitude, he means the inborn capacity of a person that enables him or her to realize and develop certain general and specific types of behavior, properties, and capacities; by talent, Révész means capacities far above the average in a special field of human activity. "If we speak of musical, scientific, technical aptitude, or of a special disposition for foreign languages, mathematics, etc., we mean by this the natire latent endowment - in other words, the fitness to give concrete and effective expression through motivation and intellectual growth and development to certain valuable properties and capacities." (1954, p. 141)

Aptitude, according to Révész, refers to natural propensity, a potential ability by which specific properties, capacities, and productive powers may be realized through interaction with environmental factors and training. "It is well known that other factors, such as environment and heredity, mental equipment, will power, morality - in a word, the total personality - also play an important role in music ability. The greatest aptitude is not sufficient in itself if goal, plan, determination, passion, and study are not called into 
play at the right moment and in the right way. If one can achieve a harmonious combination of 'spiritual,' 'innate,' and 'material environmental' circumstances, even a mediocre musical capacity is capable of outstanding accomplishments." (Révész, 1954, p. 141-142)

Aptitudes, in Révész's view, are labile, diffuse, and undefined. They are not sharply differentiated. Aptitudes manifest themselves, for the most part, in the form and direction of interest, and in a marked educability and a relatively rapid progress in the field indicated by the aptitude. In other words, the aptitude indicates fitness of performance.

A term commanding considerable attention in the literature on the nature of musical talent is musicality. Schoen (1949) like numerous prominent writers on the area, make a distinction between musicality and musical talent. The latter, he contends, refers to a capacity for musical performance, and the former to a capacity for musical reception. One may be very musical, having considerable sensitivity toward, feeling for, and appreciation of music without a performing ability; this is musicality. Another may perform in a fashion that is technically superior, and may have talent but not musicality. For genuine musical artistry, one should ideally possess both talent and musicality.

Psychologists interested in this field do not make a distinction between these terms, however. When Seashore (1938) refers to musical talent, he includes musicality. Capacity for both Seashore and Schoen refers to inborn musical talent. For psychologists, then, music capacity refers to a something with which one is born that enables one to develop fine musicianship. 
In 1919, Seashore wrote: "Modern psychology distinguishes between capacity and ability. The term 'capacity' has reference to the inborn or native power; the term 'ability' is used to designate acquired skill in the use of a capacity, for example for memory, but we develop various kinds and degrees of ability in the use of this capacity." (1919, p. 14-15)

As suggested, there is no general consensus regarding the terminology used to discuss musical talent. The differences in meaning for the term ability, as used by Révész (1954) and Schoen (1940), is a case in point; for Révész, ability is innate; for Schoen, it is acquired.

\section{THE ELEMENTAL VIEWPOINT OR THEORY OF SPECIFICS}

According to Seashore (1938) musical talent consists of a number of separate capacities which are fairly independent of one another. Existing work on the properties of the sound wave provided a starting point for his own theorizing. In 1919 he wrote: "Musical talent is not a single talent, it is a hierarchy of talents, many of which are entirely independent of one another. Therefore, a description of a musical mind reduces itself to the picturing of the relative prominence or latency of each musical talent. The talents naturally group themselves so that we have the tonal group, the rhythmic group, the motor group, the intellectual group, and others." (1919, p. 6)

In the tonal group there is pitch, defined by the frequency of the sound waves; loudness defined by the amplitude of the wave; time defined by the duration of the wave; and timbre defined by the quality of the wave. Thus, there is a perfect psychophysical parallelism - each function of the mind has 
a physical counterpart.

Since the various elements or talents of pitch, loudness, timbre, time, etc., are independent of each other, one may possess any of all to a high or low degree. Working from the hypothesis that an individual who can discriminate small differences in these qualities would also be a superior musician, Seashore devised a set of tests to measure individual differences. "On the basis of our experiments in measuring the sensory capacities we find that the basic capacities, the sense of pitch, the sense of time, the sense of loudness, and the sense of timbre are elemental, by which we mean that they are largely inborn and function from early childhood. After a comparatively early age, they do not vary with age except when limited by the child's ability to understand and apply himself to the task..." (Seashore, 1919, p. 3)

In Seashore's view, the presence of at least minimal sensory capacities are fundamental to musical talent. Musical imagery, imagination, and memory are also important components. In contrast to the innate sensory powers, musical imagery, it appears, can be developed with training. A good memory, although a great asset, is not an essential condition for musical talent. Seashore includes musical feeling and performance in his componential analysis. Feeling includes not only the aesthetic experience but also a "creative feeling" as it exists, for example, in the composer. This structuralist viewpoint requires that the expression of feeling comes through the sensory media. Musical performance is therefore limited by certain inherent and inherited motor capacities. Musical performance is constrained by the limitations of sensory capacity. For example, one low in rhythm discrimination will, of necessity, be low in rhythm performance. Seashore readily admits that his is an atomistic 
viewpoint. He believes, however, that it provides a basis for classification and makes possible an analysis and evaluation of musical talent.

A view that has a great deal in common with Seashore's, and indeed may be said to be a variation of the theory of specifics, is held by Schoen (1940). He agrees that musical talent is made up of a number of capacities, but differs from Seashore regarding what the capacities are, and which are most important. "Musical talent...consists of scores of individual, elemental, specific capacities each contributing its share to the making of the artist. These specific talents may be summarized under four heads, viz., musical feeling, musical understanding, musical sensitivity, and musical virtuosity forming the affective, the intellectual, the sensory, and the motor basis for musical artistry..." (1940, p. 162)

According to Schoen (1940), an inventory of musical talent is possible within these four areas. Talent factors include auditory sensitivity (the same as Seashore's sensory capacities: pitch, loudness, timbre, time), musical feeling and understanding (these include absolute pitch, tonal memory, tonal and harmonic sequence, consonance and rhythin), and musical virtuosity (inherited motor capacities).

Among the secondary factors contributing to talent, Schoen includes intelligence, musical memory, will power (persistence in music), self-confidence, and temperament. By temperament he identifies an acute sensitivity to things that are beautiful and the need for a medium of emotional expression.

While both theories recognize the importance of sensory capacities, Seashore 
places a greater importance on them. Schoen emphasizes the affective and intellectual side of the musical mind. Both theorists follow an elemental analysis of various independent capacities, and both are entirely dualistic.

An alternative, and more recent view of musical talent, has been provided by Lunden who states: "Let us abandon this type of reference to inherited psychic powers of the mind and limit ourselves by defining capacity as the limiting influence of biological structures. For the modern psychologist, capacity for musical performance is possible. This capacity includes, among other things, a sound nervous system, two hands, normal hearing structures, and other structures necessary for musical behavior." (1967, p. 217)

Capacity, then, is a biological potential serving as a framework within which we develop musical actions. By capacity is meant biological capacity, not inborn behavior patterns or powers of the mind. Ability, on the other hand, refers to acquired skill. Musical abilities refer to such skills as the ability to discriminate different pitches, intensities, and intervals, or the ability to harmonize melodies, sing at sight, or perform on an instrument. These abilities, maintains Lunden, are learned to various degrees of proficiency.

Lunden (1967) defines talents in music as being dependent on one another. The talents are capable of being trained to various degrees of proficiency providing one has sound biological equipment. He recognizes that individual differences exist and that not all people with similar training achieve the same degree of proficiency in musical tasks. The principle of individual differences operates in musical behavior as in other kinds of responses. 


\section{A BEHAVIORAL VIEW}

The behaviorist view of musical talent attempts to get as close to the "facts" as possible. Musical ability is not regarded as a single trait possessed in various degrees by individuals. It consists, rather, of a number of acquired inter-related behaviors, built up through a process of interaction of individual organisms with musical stimuli throughout their life history. Thus, an individual interacts with various stimuli and acquires responses to them. In this context, the term "musical mind" is useless because the object of inquiry is the actual response a person makes, not some psychic capacity stored away in one's head or in one's nervous system.

\section{OMNIBUS THEORY}

Mursell (1937) proposes a theory of musical talent strikingly different from other writers. He maintains that musical talent depends upon perception of the dynamic relatedness of tone. He does not believe in instinct, faculty, or special ability. Musicality is a combination of mental processes of which there are three basic ones: 1) affective responsiveness to tone and rhythmic patterns, 2) perceptual awareness of tonal relationships, and 3) perceptual awareness of rhythmic groupings. One individual may be more responsive, or capable of perceiving much more refined relationships than another. According to Mursell, musicality does not depend directly on sensory ability, as Seashore and Schoen suggest. Instead, psychological capacities, upon which musical behavior depends, are found in various degrees in widely differing combinations. The most fundamental of these, asserts Mursell, is a general emotional responsiveness to tone that can manifest itself without any clear apprehension of the structural elements. This emotional responsiveness in- 
volves no discrimination or selective awareness of music as a pattern where expressive significance depends upon its organization. A undifferentiated response to tonal content, contends Mursell, is probably never found without some awareness of the structural and relational factors.

\section{THE NATURE OF TALENT}

Révész (1954) points out that no one is, or ever has been capable of exceptional accomplishments in several unrelated fields. Talents that have achieved great success in different areas have seldom evinced productive powers in more than two directions. Among such cases is Leonardo da Vinci whose genius manifested itself in two areas: painting and technique. Otherwise, talent appears to be a question of domains that are intimately associated with one another. Michelangelo, who was a painter, sculptor, and architect, remained in the realm of representational art. Decartes and Leibnitz, who made immortal names for themselves as philosophers and mathematicians, did not go beyond the boundaries of the abstract sciences.

Accordingly, maintains Révész, within each of the primary domains of science and art there is one homogenous talent that covers the entire field. Although this viewpoint is at variance with the prevalent conviction that creative work in the essentially independent provinces of science and art is linked with special talents, the conflict of viewpoints can be eliminated by drawing a distinction between type and direction of talent.

By type of talent is meant an integral homogenous capacity in a distinct activity. In the course of the individual's life, such a preformed special talent can, as a result of inner and outer factors, take different directions 
characterized by an increased interest for a special field. This interest lends, in turn, a special structure to the original homogenous talent which can easily give the impression of a particular type of talent.

The organic totality of the creative talent manifests itself in all departments of human activity, Révész contends. This is particularly evident in the realm of music. With very few exceptions, the great composers wrote in nearly all genres. Henry Purcell, the leading exponent of English opera, composed not only an opera and a large number of stage works that were styled operas, but also church music, arias, and incidental music for plays, songs, chamber music, works for solo instruments, etc. Mozart's compositions included church music, symphonies, operas, choral works, Lieder, chamber music, concertos, and compositions for piano, violin, and flute. Beethoven wrote church music, choral works, symphonies, chamber music, music for solo instruments, an opera, and ballet music. Debussy composed chamber music, choral and orchestral works, and music for the piano and the voice. The same is true of Bartok, Ravel, Stravinsky, Richard Strauss, and numerous others. (Révész, 1954)

In view of these considerations, there seems little ground for assuming special talents for the principal branches of music. Everything seems to point to the fact that one-sidedness, the limitations of creative ability to a special genre or field, is due to direction of interest, to special training, to the intelligence of an inspiring personality, to the specificity of physical environment, to the general intellectual background and the fundamental disposition of the person in question. In the productive musician, specializing in a particular activity is largely due to one's disposition or to 
one's attitude towards work and life. The individual's fundamental "temperament," to use Révész's (1954) term, can be lyrical (subjective sensitive) or epic-dramatic (active emotional). These fundamental moods and sensitivities reveal themselves in the artistic performances in all provinces of art. It becomes easy to understand, therefore, how it is possible to speak with equal justification of lyrical poetry and lyrical music, of dramatic literature and dramatic music.

\section{VARIANTS OF MUSICAL TALENT}

It has been suggested (Révész, 1954), that musical talent may be differentiated into two types: creative and reproductive-interpretative. The latter may be subdivided into instrumental virtuoso talent and talent for conducting. Although both the creative and the reproductive-interpretative talents are sometimes found in one person, they still represent two highly independent and altogether distinct types of talent. This is evidenced by the fact that the two do not usually go together. Few of the great violinists, organists, pianists, and conductors were distinguished composers. Even though they often engaged in creative work, they nevertheless very rarely succeeded in producing works of high musical value. Their compositions lack originality, show the influence of really great composers, and bow to current taste. Similarly, eminent instrumentalists find it difficult to produce anything outstanding for the simple reason that virtuoso performance on any instrument demands such a great inward absorption in a composition not one's own, such a degree of self-control, and such specialized technical training, that there is hardly any energy or time left for development of a creative ability. 
In contrast to the above, it happens much more often that eminent composers distinguish themselves at the same time as executant artists. Any kind of musical training requires the playing of some instrument, and training in composition and creative ability are hardly possible without the command of at least one solo instrument. Further, with young musicians circumstances are rarely such that they can devote themselves exclusively to compositions at the beginning of their careers.

PREMATURE EMERGENCE OF MUSICAL TALENT

It is not insignificant that within the realm of art, music is the only one that manifests itself during childhood. Although its premature emergence is almost exclusively limited to technical instrumental abilities, there are also cases in which very young children play delicately and softly with flexibility when art calls for it, and forcefully with precision and passion when dynamic accent is required. They know perfectly well when the melodies have to be played with a singing legato tone, and when they must be accented.

The emergence of musical-creative talent in childhood is much rarer, however. Hayden is one of the few great musicians in whom creative talent manifested itself very early. The same was true for Mozart, who is said to have written charming pieces for the piano before he was six years old.

In most cases it has been found that the early emergence of the creative gift appears during the first half of youth, and only in exceptional cases during puberty, i.e., before the 13th or after the 18th year.

Why music, of all artistic talents, has the distinction of early emergence 
and rapid development is not easy to answer. One reason may be that creative music ability has much less to do with the functions of thought and speech than reproductive work in any other field of art. Music creates its forms and material totally out of itself. As a result, the performing musician in his or her development is bound very little to knowledge of other fields. Additionally, music is anchored in the emotional world, in a sphere to which youth also has free access. Where these factors are considered one encounters a logical and consistent explanation for the early emergence and rapid development of musical talent.

\section{INHERITANCE OF MUSICAL CAPACITIES}

It has been noted that blood relations, especially parents and children, grandparents and grandchildren, manifest similar traits. These family resemblances are not limited to only physical likeness, but such qualities as temperament, character, iritelligence, and talent. In most cases, the part contributed by both factors can only be estimated with more or less probability. In the inordinately talented, as well as the inordinately untalented, heredity is likely to predominate. A case in point is Beethoven, whose environment, including his education and training, could never account for his great musical outpouring. (Révész, 1954) The dominating influence of native talent is shown even more clearly in the case of artists who produce works of value during their childhood. With Mozart, environment and education were certainly important factors, but his ability to compose notable music by the time he was ten years old strongly points to a congenital disposition.

The systematic investigations of the inheritance of inborn musical capacity by Dutch scientists Heymans and Ziehan (1922) are of interest. Heymans and 
Wiersma had 432 well educated subjects complete a questionnaire describing the mental and emotional characteristics of parents and children within their nuclear family group. Among the questions asked was one regarding the so-called "musical ear" - an index of musicality. When both parents possessed good musical ears, it was found that 84 percent of the musically talented and 10.4 percent of the unmusical children derived from parents of equal talent. With untalented parents the ratio was reversed. The percentage was 29.7 percent musical and 62.5 percent unmusical children. Parents divergent in musicality gave birth to relatively large numbers of musically talented children - 59.4 percent.

In related research, Haecher and Ziehera (1922) found evidence which supported the research efforts of Heymans and Wiersma. Haecher and Ziehera tested 485 musical persons in a heredity test. Test subjects were graded into five categories according to the degree of their musical aptitute (extremely musical, very musical, moderately musical, unmusical, absolutely unmusical). Their test showed that with parents of equal musical talent, the chance that a child will be very musical is 85 percent, about 60 percent when the parents are unequally talented, and 25 percent when the parents are without talent. Further, it was found that the musical disposition is inherited to a greater degree from the father than from the mother. These findings refer, however, to persons of average musical ability and not to outstanding musicians.

Schoen (1940) and Seashore (1938) have no doubt that one's talent is entirely a result of natural endowment, occurring in varying degrees. According to Schoen: "Musical talent is first an inborn capacity. Artistic musical performance rests ultimately on innate, inborn equipment. It is not something 
that is acquired in one's lifetime, but the person is born with or without it. All that training can do is develop that which already exists potentially..." (1940, p. 162) Talent, in this view, is a gift nature bestows unequally upon different persons. There exists the extreme talent of the musical genius at one end of the continium, the no talent at the other end, and all degrees of talent in between. There is, further, the person who is equipped by nature with the sensory, the affective, and the intellectual basis for talent, but is deficient in the motor or technical requisites for effective musical production.

Seashore (1938) unquestioningly and dogmatically voices a strong argument for heredity: "Family pride, musical and social history, investment in musical education, the making or breaking of a career, hinge upon adequate evaluation of talent; and talent, by definition, is an inherited trait. The world talks glibly of it in high praise and in deep disparagement, often without a glimmering of a scientific insight or discriminating attitude. The concept of inheritance must have a place in the psychology of talent." (1938, p. 330)

Having considered the view of psychologists interested in musical ability, it may be helpful to now consider the views of a biologist and geneticist. Scheinfeld (1965) points out that a good many composers: Chopin, Mozart, Mendelssohn, Liszt, and Schumann, and contemporary virtuosi: Heifetz, Rubenstein, Menuhin, Schnabel, Stern, and Arrau revealed their genius to the world at such an early age the environment could have exerted little influence. Mozart wrote his first symphony at age six and completed practically a score of symphonies by the time he was 14. Handel, at eleven, was writing a new church service every week; and Mendelssohn, at 17, already an exper- 
ienced composer, had written the overature to A MIDSUMMER NIGHT'S DREAM. In a study of various virtuosi and Metropolitan Opera singers, Scheinfeld reported that the average age at which talent first emerged was four and three quarters years, and nine and three quarters years for the two groups respectively.

A second line of evidence favoring the heritability of musical talent is geneology - the most quoted example being the Bach family. Scheinfeld suggests, however, that the inheritance of musical talent is a rather complex matter. A polygene or multigene theory is necessary since talent sometimes emerges where parents are not musical, and musical parents do not always beget musical children. For example, Toscanini, considered by many to be one of the greatest musicians who ever lived, came from a family in which no musical talent appeared in either of his parents, sisters, brothers, or other relatives. Rather than accept an environmental explanation, Scheinfeld suggests that Toscanini's parents had carried between them the genes for virtuoso talent. Scheinfeld admits, however, that an unfavorable environment can suppress talent. He cites the case of Leonard Bernstein, whose talent did not express itself early, but gradually emerged. In similar fashion, this suppression theory is necessary to explain, says Scheinfeld, the very small percentage of virtuosi and composers among females. Since talent, in Scheinfeld's view, is not sex-linked, the only possible hereditarian explanation is that we are prejudiced against female musicians. Of course, opera singers and other female vocalists prove, in this instance, to be the exception.

The preceeding survey of viewpoints regarding the heritability of musical talent is representative rather than exhaustive. To continue citing opinions and data in support of the various viewpoints would only underscore the ob- 
vious lack of consensus within the area. Perhaps, a look at the psychometric tools used to measure musical talent will provide a more concrete grasp of what it is that psychologists talk about when they refer to musical talent.

THE MEASUREMENT OF MUSICAL BEHAVIOR

The first 30 years of this century witnessed a considerable amount of psychometric work on music. This work proceeded primarily in three areas. Attempts were made: 1) to measure musical capacities or aptitudes, 2) to measure music achievements resulting from training, e.g., aural perception, technical abilities, and skill in reading notation, and 3 ) to measure knowledge about music. Although such a division is somewhat arbitrary, this classification provides a workable means for analysis.

It has already been suggested that considerable disagreement exists among authorities regarding the development of musical talent. Some maintain it is the function of learning, others that talent is inherited. There is similar disagreement concerning what constitutes musical ability. Thus far, measures of musical talent or ability have been largely of a sensory sort. Tests of feeling and of appreciation have tried to sample the more aesthetic responses to music, while those of knowledge deal mainly with acquired responses, such as the names of composers, notation, instruments, scales, etc.

The present discussion will concern itself, for the most part, with the testing of musical ability. It is on this area that the most serious attempts to predict musical success have been made based upon the assumption that if an individual does well on these tests he or she will be able to profit from musical training. Additionally, there are important assumptions about the 
nature and functioning of the musical mind underlying all musical tests. A consideration of these measuring devices yields important insights into the general psychology of music.

\section{THE SEASHORE MEASURES OF MUSICAL TALENTS}

The Seashore Measures of Musical Talents (1919) are quite simply the most important battery of tests in the field of music. Since their publication in 1919, the Measures of Musical Talent have been applied to thousands of individuals so that there is enough research material to make possible an adequate judgment about their value and limitations.

Although there have been several revisions of the Seashore tests, the content has remained, for the most part, unchanged. The tests comprise a battery made up of six tests: pitch, intensity, time, memory, consonance, and rhythm. The pitch test indicates a person's threshold of pitch discrimination, or the least difference in the pitch of two tones that the person can perceive. The test is made up of ten pitch increments within a frequency range of 30 cycles which are compared one at a time with a base line frequency of $435 \mathrm{cps}$. There are 100 trials in the tests, each increment being compared ten times with standard base line tone. The individual is required to make a judgment as to whether the second tone is higher or lower than the first tone. Seashore (1938) offers evidence that the results of this test are not affected by age or training. It is a test of basic capacity.

The intensity test does for loudness discrimination what the pitch test does for pitch discrimination. It is a test of the least perceptible difference in loudness that a person can detect. There are ten series of trials with 
ten trials in each series. Seashore offers evidence that loudness discrimination, like pitch, is an elemental capacity, and specialized training after early childhood does not result in improvement. The test, he concludes, is therefore one of basic capacity.

In the time test, the listener hears three clicks marking off two time intervals. The second time interval is always either longer or shorter than the first. As before, the test consists of 100 trials divided into ten series of ten trials each. The subject is required to make a judgment as to whether the second interval is longer or shorter than the first.

The consonance test is constructed of 100 two-tone combinations of various degrees of consonance. Consonance is defined, for the purposes of the test, as smoothness, blending, and fusion. The 100 combinations are arranged into pairs so that the entire test consists of 50 trials. The subject is required to make a judgment as to whether the second combination one hears is better or worse than the first. A good combination is one in which the two tones are smooth and blend, tending to fuse together into one.

Referring to the memory test, Seashore states that: "Everything taken into account, the best single and fundamental test of capacity for a musical memory test that we have been able to devise is the test of memory span." (1938, p. 239) The test is constructed to indicate one's memory span for a succession of non-melodically related tones, similar to a test of memory for nonsense syllables. The shortest span in the test is two tones, and the longest is six tones. The subject hears a sequence of tones immediately followed by another sequence. The second sequence is like the first except for one 
tone. The subject is required to specify which tone in the second sequence has changed. "The most striking result of this test" Seashore writes, "is that a span of six is difficult enough for practically all of a normal community. A person who, in an extended series of trials, is able to get all records right would have an extraordinary capacity for this kind of memory. Other things being equal, the child in the fifth grade room who ranks 85 gives promise of a memory for as extensive a repertory as any musician may need, and persons who now play programs of several hours entirely from memory may not rank higher than 90 on this scale." (p. 239-240)

The rhythm test consists of two rhythmic patterns, the second pattern being either the same as the first or different from it. There are 50 pairs of patterns in the test of varying length and complexity.

THE PSYCHOLOGICAL THEORY OF THE SEASHORE TESTS

With the exception of the test for tonal memory, the Seashore tests claim to deal with sensory capacities. This is entirely consonant with Seashore's dictum that "there is nothing in the music which was not previously in the sound wave," and implies that musical effects depend upon the action of the ear as a physical receptor. This approach represents an attempt to apply the sensationalistic position in psychology to the measurement and diagnos is of musical ability. It does not attempt to deal with such functions as melodic configuration, intervallic relatedness, harmonic sequence, resolution trends, and tonality.

Seashore has pointed out that his tests do not deal with all the factors of musicality. Numerous commentators have suggested that the tests may fail al- 
together to deal with talent, and instead restrict themselves to aural perception. Révész (1954) insists that musical talent cannot be an assembly of atomistic sensory acoustical abilities. Ogden (1924) contends that they do not directly test "...the presence and functioning of those fundamental configurations of apprehension and response without which musical talent cannot manifest itself." The primary point here is that the Seashore Measures of Musical Talent undertake merely to test the responsiveness of the ear as a receptor to certain differences in the sound wave. Mursell (1964) insists that music depends upon our perception of the dynamic relatedness of tone. It would appear, then, that the Seashore tests are more efficient in identifying those incapable of musical achievement on a high level than in the positive diagnosis of talent or, for that matter, revealing the degree to which it exists. The Seashore tests measure acoustical rather than musical abilities.

\section{THE SCHOEN BATTERY}

In this battery there are three tests (Schoen, 1925): a test of relative pitch, a test of tonal sequence, and a rhythm test. According to Schoen, these tests are measures of general musicianship. The individual's performance on these tests is supposed to indicate his or her aesthetic response to the structural material of music. The tests of relative pitch and rhythm are simply psychometric variations of the same functions markedly different. It is designed to reveal a person's sensitivity to melodic line. A melody is defined as a succession of tones differing from each other in pitch and duration and giving the effect of an aesthetic unity. The test consists of four, two phrase melodies from standard compositions. In the second phrase of each melody there are three alternative phrases as possible endings, in addition to the original 
ending. Each of the three alternative phrases is inferior to the original phrase as an ending, one being only slightly poorer, another noticeably poorer, and the other entirely inappropriate. The subject is required to evaluate the relative appropriateness of all endings.

THE KWALWASSER-DYKEMA TESTS

There are ten tests in this battery (Kwalwasser and Dykema, 1930) which measure tonal memory, quality discrimination, loudness discrimination, feeling for tonal movement, time discrimination, rhythm discrimination, pitch discrimination, and rhythm imagery. The authors maintain that experimental investigations in the field of psychology of music have established the importance of these traits as indicants of musical talent and achievement. They represent significant attributes of musicianship and readily lend themselves to objective measurement. For the most part, the parameters evaluated by these tests duplicate and overlap functions mentioned in previous tests. The most notable exceptions are, however, the tonal imagery and rhythmic imagery tests. In the tonal imagery test the subject is supplied with the notation of 25 tonal patterns containing all the chromatic characters used in music, that is: sharp, double sharp, flat, double flat, and cancel. On this test, the subject indicates whether the tones heard, produced by a record, are the same as or different from the tones called for on the printed page.

The rhythm imagery test is similar to the tonal imagery tests. The subject indicates on a test sheet whether the rhythms on the printed page are the same heard, produced by a recording, or different. 
THE ORTMANN BATTERY

Ortmann devised seven tests as objective scientifically acceptable measures of the fundamental auditory and musical capacities of students entering the Peabody Conservatory of Music. The tests are of pitch discrimination, pitch memory, and harmonic memory.

THE IOWA TESTS OF MUSICAL LITERACY

This battery of six tests, developed by Gordon (1971), is divided into two aspects of fundamental musical achievement: tonal concepts and rhythmic concepts. Each of these tests includes three subtests: aural perception, reading recognition, and notational understanding.

As can be seen, numerous attempts have been made over the years to investigate the nature of musical talent. For the most part, however, the results have not been overwhelming (Seashore, 1938; Révés z, 1954; Lunden, 1954; Schoen, 1940). The inconclusiveness of the data may be attributed, for the most part, to the inability of investigators to come to a consensus regarding a definition of musical talent. Existing psychometric devices appear adequate insofar as our understanding of what constitutes musical talent has progressed; but, our understanding has not progressed greatly in the last 40 to 50 years.

\section{THE VALIDITY OF THE SEASHORE TESTS}

The Seashore tests have had the most severe trial of their validity at the Eastman School of Music (Stanton, 1935). This project was carried on for a period of over ten years under the direction of psychologists. In one study, the test results were classified into six groups corresponding to the letter 
grades generally found in an academic setting. "A" represented the highest talent. The classification was then compared with the teacher's estimate of talent using the same letter classification. The results showed striking similarities between test results and numerous teachers' estimates of talent for various instruments and voice.

Another study indicated the value of the tests in predicting how long the pupil was likely to last in school according to his or her talent classification. Of those who tested "D" and "E," none survived two years. Of the "C-" talents, about one-fourth lasted out; of the "C+" talents, two-fifths; of the "B" talents, over one half; and two-thirds of the "A" talents lasted the two year period.

Another example of the numerous studies carried out at the Eastman School involved the addition, in 1928, of a standardized comprehension test to the pre-existing music tests. A classification of safe, probable, possible, doubtful, and discouraged, was made for the music degree students as a basis for predicting achievement. Of 565 students who graduated within four years, 60 percent came from the safe group; 42 percent from the probable; 33 percent from the possible group; 23 percent from the doubtful; and 17 percent from the discouraged.

The Seashore tests have been the subject of numerous other studies with respect to reliability and validity. Farnsworth (1931) summarizes these investigations, and reports his own experiments with the tests.

The pitch test, Farnsworth concludes, is quite high in reliability. Seashore's 
advice regarding the pitch test was that those who rank in the upper ten percent should be encouraged enthusiastically to study music, the next 20 percent encouraged freely, the next 40 percent encouraged, the next 20 percent questionable, and the next ten percent discouraged.

The loudness test is somewhat less reliable than the pitch test. Most of the conclusions on the pitch test are equally applicable to the loudness test.

The reliability of the time test is generally regarded as low. One of its disadvantages is that its unmusical manner of judging time is disturbing to many students who have had musical training. It is, furthermore, sometimes difficult to make the directions clear.

The consonance test has been most severely criticized by investigators. It has been found to be of questionable value because different subjects understand the directions in different ways. Its criteria for consonance have also been seriously questioned. The loudness factor is not constant. This results in certain combinations being rated higher or lower than would be the normal case. Farnsworth (1934) points out, however, that in spite of its faults and unreliability, it is perhaps well to keep in mind that the errors made by groups of subjects are quite consistent.

The tonal memory test, like the pitch test, is one of the most reliable members of the battery. One of its disadvantages is that as the number of tones increases, subjects become discouraged.

One may conclude, then, that the pitch and memory tests appear to possess sufficient reliability for certain diagnostic purposes. The others should 
only be used with extreme caution. The reliability of the entire battery is .885 , with that of pitch being .75 , loudness .66 , time .51 , consonance .65 , rhy thm .47 , and memory .83 .

\section{STUDIES OF THE SCHOEN, KWALWASSER-DYKEMA AND ORTMANN BATTERIES}

The only study of the validity of the Schoen tests is one made by Schoen himself (1923) in cooperation with several music teachers. The tests were given to pupils selected by the teachers as being most talented, least talented, and mediocre. At the time the tests were given, the investigator knew nothing about the pupils regarding degree of talent or accomplishment, except that the subjects possessed various degrees of endowment and attainment. A report was issued for each pupil giving his or her rating on the tests. On the basis of the test results a prediction was made concerning the pupil's probable accomplishment, given proper instruction and adequate application in six factors of artistic musical performance: intonation, tonal quality, shading, variety in performance, phrasing, time, and rhythm. A blank was then sent to each teacher asking for an evaluation of the actual attainment of the pupil on these factors. The purpose of this procedure was to test the predictive value of the tests by determining the degree to which actual accomplishment, as judged by the teacher, would agree or disagree with the predictions of accomplishment based on the test results.

In summarizing the results, out of a total of 70 evaluations there were 49 complete agreements between teacher and tests, and 21 disagreements.

The utility of the Kwalwasser-Dykema test battery has been investigated by Farnsworth (1934). This battery has five tests which overlap five of the 
Seashore tests. That is, they supposedly measure the same capacity: pitch, rhythm, loudness, memory, and time. In one of his investigations, Farnsworth (1934) attempted to find out how the pairs of similar tests correlated with each other. He gave the tests to sophomores at Stanford University and found that, with the exception of the tests of tonal memory, the tests were not measuring at all perfectly the same behavior variables. These findings were verified by a similar investigation by Tilson (1936) on college students enrolled in a music supervisor's course.

The reliability of the tests has been found by nearly all investigators to be low. The tonal memory is the best of the battery. The reliability of the Kwalwasser-Dykema battery is .77. Farnsworth (1941) has concluded that with the possible exception of the test of tonal memory, the Kwalwasser-Dykema tests are too unreliable for individual prognostication. Comparing the Kwalwasser-Dykema with the Seashore, Farnsworth's study indicates that the Seashore tests are superior psychologically, and more reliable than the Kwalwasser-Dykema battery.

The validity of the Ortmann tests is reported by Ortmann to be higher than that obtained for the Seashore tests in 20 investigations. Their reliability, as indicated by the results from 50 students who took the tests twice, 44 after one year, seven after an interval of two years, three after four years, and one after five years, is reported to be fairly high and adequate for individual measurement in the case of the average test score and the score on memory for a simple tone. The others are generally regarded as low and inadequate for individual measurement, al though useful for group averages 
and school surveys.

THE ANALYSIS OF MUSICAL TALENT THROUGH STATISTICAL TECHNIQUES

One of the first factor analytic studies in this area was conducted by Drake (1939), who analyzed a number of different tests including tonal memory, pitch, rhythm loudness, tonal movement, and general intelligence. He came to the conclusion that there was a general factor of musical ability common to all measures.

McLeish (1950) analyzed the Seashore tests and found a general factor of musical ability and appreciation, a bipolar factor, and several specific factors. He identifies the general factor as musical ability and appreciation. The bipolar factor is a classification factor. It subdivides the six tests according to their concrete content, contrasting: 1) those that depend chiefly on immediate discrimination, and 2) those depending on immediate memory. The specific factors are for pitch, loudness, time, and rhythm.

A recent analysis by Rainbow (1965) found pitch discrimination, rhythmic sensitivity, and musical memory to be the predominant constituents of musical ability. His results indicated extramusical variables to also be relevant to talent. These variables include: 1) interest in music, 2) home enrichment, 3) academic intelligence, 4) socioeconomic background, and 5) musical training. He suggests that if one wants to predict whether or not a person will be a success in music, the accuracy of prediction will be improved by giving consideration to these relevant extramusical variables.

Surveying these statistical studies and others, it becomes clear that there 
is little agreement as to what constitutes musical aptitude. The factors that emerge depend to a large extent on the particular music tests employed in each study. When a number of different studies employ different tests, it is not unusual that different results will emerge. No single test or battery of tests measures all the facets of musical ability; and, as Anastasi (1961) points out, the field of musical aptitude testing has lagged behind other areas of psychological measurement.

The preceding has sought to provide a survey of the thinking and tests which have evolved in an attempt to define and empirically specify the nature of musical talent. Bently (1966) concludes there is no simple answer to the question "What is musical talent?" The difficulty, it seems, is that there is no generally agreed upon criterion or definition of musical talent. Many attempts have been made to understand it, and measure it; but, the nature of these attempts, concludes Bently, "depends more upon belief than upon scientifically proven conclusions." (1966, p. 142)

\section{THE NATURE OF TALENT}

A precise definition and, more importantly, an understanding of the nature of musical talent has indeed eluded previous researchers. This is not to suggest, however, that previous research efforts are without merit. To the contrary, they have been invaluable in specifying the sensory, the motor, and the intellectual components which all play requisite parts in the more general phenomena called talent. But, musical talent is something more than the summation or interrelation of these abilities. Talent is more than technique, even virtuosic technique. It contains a creative component. It is this 
creative aspect of musical talent that distinquishes the flawless yet sterile technical recitation of notes from meaningful and communicative achievement. As Child (1967) suggests, we need to recognize that a piece of music is a psychological, as well as a physical event. What this psychological event is to the listener is its meaning. The meaning is not found in an account of the physical sounds; it must be found in an account of the psychological experience. Given the technical competence, then, of a master performer, a composer or a conductor might still lack the ability to imbue his or her work with genuine meaning. The musician under such circumstances would be said to lack talent.

\section{THE PSYCHOLOGY OF MUSIC AIND ART}

The ability to communicate musically requires involvement on the part of the musician, an infusion of the musician's being or personality into the musical medium such that sequences of notes are enlivened under the influence and experience of the musician. When music is able to communicate the individual musician's personal experience with life, it becomes an expression of the musician's personality. To the extent hearers of the music can identify and respond to this personal involvement, on the part of the musician, the music will be psychologically meaningful for them.

Numerous writers have addressed this creative synthesis of the artist's personality and his or her art. Much of the literature on this theme stems from Freud's analysis of nocturnal dreams, errors, and neurotic symptoms.

"The ordinary person's ability to create daydreams suitable for resolving conflicts is very limited. "The artist is a specialist of high skill and has more at his disposal. "First of all he understands how to elaborate his daydreams, so that they lose that personal note which grates upon strange ears and become enjoyable to others; he knows too how to modify 
them sufficiently so that their origin in prohibited sources is not easily detected. "Further he possesses the mysterious ability to mold his particular material until it expresses the ideas of his phantasy faithfully; and thus he knows how to attach to his reflection on his phantasy life so strong a stream of pleasure that, for a time at least, the repressions are outbalanced and dispelled by it. "When he can do all this, he opens unconscious sources of pleasure and so reaps their gratitude and admiration; then he has won through his phantasy what before he could only win in phantasy: honor, power, and the love of women." (Freud, 1952, p. 384-385)

The artist, as depicted by Freud (1952), is represented as dually, but not distinctively motivated. On the one hand, he or she is like most other people, motivated realistically toward economic success. On the other hand, like others, he or she is subject to motives which cannot be gratified in reality or acted out in society that urge one on to fantasying gratification and resolution. The artist's distinction is that these two sets of motives unite to find expression in a single sequence of behavior: producing art in fulfillment of one's longings, marketing it to those who in contemplation of it will fulfill their own. This view of Freud's stresses the importance of unconscious motives and their fantasized fulfillment, but finds nothing distinctive about the artist in this respect.

Child (1969) points out that the artist is claimed to be distinctive in the ego, not the id, and in skills, rather than motives. His id is essential to the argument, but only through its similarity to other people's.

It is apparent that only a slight change in emphasis is needed to produce a theory relating distinctive motives of a particular artist to distinctive characteristics present in their productions. As Child remarks, "If the more universal thematic characteristics of a work result from universal motives necessarily present in the artist, why should not its more specific characteristics result from his motivational peculiarities? And for that matter, should not 
even the more universal themes - universal in characterizing every person, but not every work of art - vary in intensity and manner of representation, even perhaps in whether they appear at all, according to the intensity and salience of various universal motives in the artist's personality or temporary state?"

In the years since Freud, psychoanalytic commentators have used this argument in inferring an artist's personal characteristics from his work. Since the themes of literature lend themselves more readily to this approach than do the material of other arts, the artists most often studied in this way have been writers. Sometimes, inferences to personality or life history are presented solely on the basis of contact with the art work. Inference to an artist's personality and life, from analysis of his or her works, need not, however, be based only on the psychoanalytic portion of psychiatry and psychology. Some essays that draw other aspects of psychology are Rosenzweig's (1943) on Henry James; Murray's (1951) on Herman Melville; and Trilling's (1940) on Freud.

Various hypotheses have been suggested about the nature of the relationship between artists and their works. These have arisen from such considerations as: does the artist's work primarily embody his or her own manifest personal characteristics? Does it primarily embody those latent characteristics? Does it primarily embody those latent characteristics which fail to gain expression in overt interaction with other people? $0 r$, is the relation between artist and work more likely to embody, in symbolic form, the ideal object of powerful wishes that have been consciously rejected. 
THE INTERRELATION OF MUSICAL TALENT AND PERSONALITY

Attempts to study the interrelation of musical aptitude, musical achievement, and personality traits, although long the subject of subjective speculation, have rarely been made. The results of most of the relevant studies are inconclusive and frequently the procedures and criteria employed are not consistent with current techniques of experimental research design.

Early attempts at a systematic study of psychological traits of musicians were based largely upon biographies and observations. (Thayer, 1972) In some studies, as suggested already, psychoanalys is has been employed in an attempt to explain artists. Only in a relatively small number of investigations have standardized measuring instruments been used to compare musical aptitude and/or achievement with personality traits.

Several possible explanations for the ambiguity regarding data on the relationship of talent and personality can be offered. Biographical accounts in which historical narrative, introspection, and retrospection are employed necessarily result in subjective conclusions, regardless of whether the goal is an analysis of musical ability or personality. A number of studies dealt with populations that were homogeneous with respect to musical training or musical interest. (Barth, 1961; Gardner, 1955; Cooley, 1961) Some investigations were concerned with abnormal personality only, and the nature of the deviations from the norm were frequently poorly defined.

Basic to an understanding of possible relationships between musical talent and personality traits are adequate and objective definitions, valid criterion 
measures, and good experimental design. One study that achieved these criteria is that of Schleuter (1971). Using factor analysis, Schleuter investigated the relationship between specific personality dimensions and measures of musical achievement and aptitude. No systematic relationship was found. Thayer (1972) conducted a similar investigation and, likewise, found no systematic relationship between the two variables.

An earlier study by Gardner (1955), although not nearly so rigorous, suggests that certain personality traits are important for musicianship. Using a group of musically select high school students from the midwestern United States, Gardner found that contrary to popular opinion and literature regarding the nature of the musician, the young amateur musician is an active, highly intelligent individual with a wide range of interests, abilities, and activities both in and out of music. The musicians were found to be leaders among their classmates, above average in academic achievement, and to come from above average homes. As individuals, the musicians were found to be a little less objective and somewhat less adept in their personal relationships than other students.

The males were found to be less active, less emotionally stable, and less masculine in their interests, while the female musicians were found to be less restrained and less friendly.

\section{INTROVERSION/EXTROVERSION}

The British psychologist H. J. Eysenck has conducted notable personality research using the factor analytic technique, and is perhaps best known for his efforts in the area of introversion/extroversion. Eysenck has consistently 
found, in analyzing personality data by factor analysis, two re?atively stable dimensions: 1) introversion/extroversion - a bipolar concept, and 2) emotionality. Eysenck regards these dimensions as non-primary. He sees impulsiveness, sociability or acitivity as primary, with introversion/extroversion as secondary factors based upon the observed correlations between different primary factors. There are, moreover, four levels of description from which Eysenck draws his factors. At the lowest level, one simply describes specific responses such as "goes to a party on Friday." If such specific responses occur with some regularity, the level of habitual response is reached - "goes to a party once or twice a week." If this sociable habit can be shown to be related to other sociable habits - likes to talk to people, has many friends, does not like solitude - then one reaches the trait level and it now becomes possible to talk about a trait of sociability. If we observe that people who are sociable are also impulsive, active, lively, and excitable, then we may postulate a descriptive concept of extroversion.

Mcdougall (1929), in suggesting the existence of a biological basis for introversion and extroversion contends that the marked introvert is one in whom high levels of activity in the cerebral cortex exert inhibition on all lower nervous functions. "We are most familiar with this inhibitory influence of cortical activity in the case of the spinal reflexes. We know that cortical activity depresses or inhibits the spinal reflexes, and that destruction, impartment, or arrest of cortical functions releases the cord from this inhibitory influence (1929, p. 203)." The introvert, then, is one on whom the lower levels of the nervous system are constantly subject to a high degree of inhibition by the higher cortical activities. Of these lower inhibited functions, the most important are the affective or emotional-conative functions 
of the thalamic regions.

The introvert, by reason of the dominant activity of the cortex and its consequent inhibitory effect on emotional expression, is an individual in whom thought appears to flourish at the expense of emotion. It is not that the introvert is incapable of emotion or strong affect, but rather that the affects do not readily find outward expression; they are absorbed in and disguised by the supervenient cortical activities and the consequent arousal of conflicting tendencies. The introvert seems relatively cold and expressionless; he or she cannot easily let themselves go; emotional expressions, both verbal and gestural, are very moderate and restrained, even when strongly moved. The introvert tends to be over self-conscious and introspective; and, this adds to his or her general inhibitedness. Additional research (Eysenck, 1967) has shown that introverts, although characteristically higher in cortical arousal than extroverts, nevertheless have lower sensory thresholds than extroverts.

The extrovert, by contrast, is an individual with a characteristically lower level of cortical arousal and higher sensory thresholds for stimulation. The extrovert does not, as a rule, demonstrate the same degree of inhibition of all emotional expressions that the introvert does. Emotional conative excitement finds outward expression in the extrovert, rather than being largely dissipated in cortical activity.

In view of these considerations, what relationship might one expect to find between personality and musical talent with respect to introversion/extroversion? Taking the Eysenckian model as a launching point, one might expect to find talented musicians demonstrably higher in extroversion than introversion when compared to a group of individuals with little or no musical ability. 
The extrovert, it will be recalled, is emotionally a more demonstrative individual than the introvert. Few would attempt to argue that performing artists are non-emotive, non-expressive individuals.

On the other hand, one might expect to find introverts in large numbers among the talented musicians, since introverts are notably more sensitive to stimuli than extroverts, and hence more likely to be perceived as "sensitive" individuals - an idea consonant with the stereotyped view of the musician. It should be noted, however, that "sensitive," for the purpose of this research, can be better expressed by the term perceptive. "Sensitivity" shall be understood to mean emotional lability - a characteristic consonant with Eysenck's view of the extrovert.

Smith (1968) found that introverts have significantly lower auditory thresholds than extroverts. This finding, in addition to suggesting physiological differences in the nervous systems of introverts and extroverts, also suggests that the introversion/extroversion dimension may be an important corollary or component of musical ability.

Additional data (Bakan, 1959) seems to put the talented musician in the extrovert camp. In a study dealing with the effect of a secondary signal detection task on performance in a primary signal detection task in an auditory vigilance task, it was found that the addition of a second secondary task, which greatly increased the number of signals to be responded to, resulted in improved signal detection performance in the primary task and that extroverts, who do not do as well with the primary task alone as do introverts, showed greater improvement than the introverts with the addition of the secondary task. 
It appears that extroverts are more likely to listen when there are more signals to listen for, whereas the listening behavior of introverts is less influenced by frequency, at least in the early part of the vigilance task. The data further suggests that the higher signal rate maintains the level of performance of the introverts for a longer time and reduces their tendency to show a decrement.

It becomes possible, then, to conceive of the performing musician's task as very much similar to the signal-detection task described above, although the musical task is far more complex. Such considerations as tone, timbre, pitch, balance, tension, phrasing, rhythm, and many others go into making up the multi-dimensional stimulus array. Given the enormous complexity of the stimulus event, there is nonetheless a sense in which the musical performance may be considered an aggregation of discrete stimuli. In keeping with the signaldetection analogy, it is important to note the frequency rate of the stimulus presentation. When the performing musician is engaged in the musical task, he or she encounters all of the previously mentioned stimulus modalities, and many others, at a frequency rate that is astounding. A sensory situation such as this would, in view of Bakan's study (1959), seem to appeal to the extrovert.

An artist constantly communicates with his or her growing work of art. As the work grows, its communicative power inbues the artist as much as the artist gives to the work. Beethoven (Révész, 1954) attested in his notebooks how specifically transformed he was by the music he wrote - each symphony creating a special world within him even as he was creating it. This symbiotic relationship between the artist and the art, this oftentimes inexplicable flowering that takes place as an artist creates a sensory array, attends to it with uncompromising vigilance, and in turn is transformed and imbued emo- 
tionally by the stimulus array of his or her creation such that he or she then externalizes the emotional experience by reinvesting it in the performance is, in the view of this writer, the essence of musical talent.

\section{HYPOTHESIS}

In view of the preceding considerations, and the widely noted observations that artists differ from non-artists, with respect to parameters other than talent, the following thesis is presented: talented musicians differ from non-musicians with respect to personality. One personality dimension on which musically talented and untalented individuals may be differentiated is introversion/extroversion. 


\section{METHOD}

\section{Subjects}

A total of 60 subjects, 32 males and 28 females, participated in the study. Subjects were assigned to one of three groups (20 each) based upon the following criteria:

1. Low Talent Group - The low talent group was composed of individuals who have virtually no musical ability. These are the "can't carry a tune in a bucket" type of individual. Low talent individuals are persons who, at some point, received musical training, but were unable to benefit substantially from the training. Low talent individuals have a normal liking for music, but are unable to express themselves musically. If asked, "Do you have any musical ability?," the low talent would convincingly answer, "No." A list of criterion questions to determine inclusion in the low talent group is presented in Appendix 1.

2. Pre-professional Group - The pre-professional group was composed of music majors selected from university music departments. The students were selected by their professors as representing the most talented individuals engaged in study - those students for whom success as a performing artist seemed assured.

3. High Talent Group - The high talent group was composed of individuals who had been, or who are, currently engaged in international careers as performing musicians, who are principal players, first chairs, in symphony orchestras, or who are faculty members in university music departments. In 
the latter instance, expert opinion, consensus among department members regarding the presence of musical talent, was substituted for a career as a performing artist.

The three groups were chosen in this manner so that: 1) the personality structures of the highly talented and the non-talented individuals might be maximally differentiated, and 2) the personality structures of the talented musicians might be differentiated from the talented musicians who chose to pursue a career as a performing artist. This distinction acknowledges factors, in addition to talent, which contribute to a successful career as a performing artist.

\section{MATERIALS}

Form $C$ of the 16PF was employed to assess the subject's personality structure. This variant of the personality profile was used because it was felt that alternative forms, requiring longer administration times, would seriously decrease subjects' willingness to participate.

\section{PROCEDURE}

Participants in this study were recruited in the following manner: for the High Talent Group, names of musicians were selected from Who's Who in America. A letter was sent to the prospective respondant explaining the purpose of the research and requesting his or her participation. Letters were similarly sent to principal (first chair) orchestral members requesting their participation. University faculty members were recruited via requests made through the chairmen of the respective music departments. 
Subjects in the pre-professional group were selected by university faculty as meeting the previously mentioned criterion. They were contacted by letter to determine their willingness to participate.

Subjects in the low talent group were recruited via ads run in campus newspapers and by requests made for volunteers in undergraduate psychology courses. Propective subjects were similarly contacted to explain the purpose of the research and to confirm their willingness to participate.

Each subject knew beforehand the purpose of the experiment and in which of the three groups he or she would be participating. No deception was involved. Each subject was mailed a test packet containing the 16PF for $\mathrm{C}$ instructions for filling out the questionnaire, and a pre-addressed, stamped envelope for returning the completed materials. Since the nature of the information requested on the 16PF might conceivably have been relevatory of sensitive personal areas, each respondant's anonymity was assured. The subjects were not required to identify themselves with their answers. The packets, returned by mail, were pre-coded to determine into which of the three groups the respondant belonged. 


\section{RESULTS}

\section{Factor Analysis}

Individual sten scores for general population - females, 16PF form C, and general population - males, $16 \mathrm{PF}$ form $\mathrm{C}$ were used for 32 males and $28 \mathrm{fe}-$ males to analyze second order factor scores via Cattell, Eber, and Tatsuoka (1970). Analysis yielded five factors which were interpreted as: 1) Anxiety, 2) Independence, 3) Exvia, 4) Perseverance, and 5) an Analytical/Creative component. A substantial factor loading for perseverance was found for talent. The five factors and their constituent parameters are presented in Table 1.

\section{Analysis of Variance}

A two way analysis of variance was performed on a $2 \times 3$ design: sex by levels of musical talent: 1. Low, 2. Pre-professional, and 3. High. The ANOVA was significant for conscientiousness $F(2,54)=6.05, P<.05$, and for age $F(2,54) 5.66, P_{<} .05$. Although not significant at the .05 level, the ANOVA revealed positive linear relationships across groups for the following factors: controlled - follows self-image, self-sufficiency, imaginativeness, sensitive, guilt proneness, super ego-persistence, and impression management (motivation distortion).

\section{Pearson Product Moment Correlation}

A Pearson Product Moment Correlation was performed on the first order sten scores of the 16PF form C, and on second order factors Exvia, Anxiety, Independence, Cortertia, Age, Sex, and the Criterion Factor for Creativity to 
assess the total structural configuration of significant correlations. Significant relations are presented in Table 2 . 
TABLE 1 .

TABULAR RESULTS OF FACTOR ANALYSIS

Impression Management
Sizia/Affectia
Intelligence
Ego Strength
Dominance/Submission
Desurgency/Surgency
Super Ego Strength
Threctia/Parmia
Harria/Premsia
Alaxia/Protension
Praxernia/Autia
Shrewdness
Guilt Proneness
Radicalism
Self-Sufficiency
Self-Sentiment
Ergic Tension
Age
Sex
Talent
Extroversion
Anxiety
Independence
Cortertia
Creativity

Factor 1

Anxiety

$-0.64087$

$-0.10933$

$-0.32749$

$-0.73443$

0.29833

0.09681

$-0.09138$

$-0.07166$

0.23735

0.47200

0.00200

0.32535

0.77448

0.08014

0.06620

$-0.50585$

0.80561

$-0.01985$

0.27451

0.08126

0.02439

0.97153

0.11501

0.10247

$-0.00051$
Factor 2

Independence

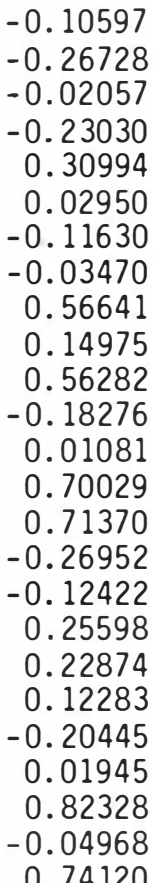

Factor 3

Extroversion

\subsection{7}

0.18500

$-0.05053$

$-0.02384$

0.54255

0.82118

$-0.04612$

$-0.77719$

$-0.07525$

0.20183

$-0.29793$

$-0.21349$

$-0.16643$

0.10159

$-0.18181$

$-0.05817$

0.28041

$-0.14109$

0.09674

0.00775

0.87949

0.05260

0.30422

0.69053

$-0.16559$
Factor 4

Perseverance

\subsection{6}

$-0.02379$

$-0.22044$

0.03315

$-0.15522$

$-0.14031$

0.58944

0.08883

0.06817

0.00670

0.17140

0.09669

0.09189

0.01508

0.08239

0.39731

0.09154

0.61205

0.04082

0.68626

$-0.02008$

0.01468

$-0.09719$

$-0.14163$

0.02497
Factor 5 Creativity

$-0.06460$

$-0.78312$

0.28631

0.09867

0.08917

$-0.18859$

$-0.12396$

$-0.02980$

0.10969

$-0.17612$

$-0.12865$

$-0.03659$

0.14579

0.04353

0.28298

$-0.07380$

0.04922

$-0.04147$

0.04721

0.18568

$-0.34580$

0.02748

0.01864

0.30700

0.51948 
CORRELATIONS BETWEEN TALENT AND THE 16PF PEARSON PRODUCT MOMENT CORRELATION

\begin{tabular}{|l|l|l|l|l|l|} 
FACTOR & $\begin{array}{l}\text { G } \\
\text { Concientious, } \\
\text { Persevering }\end{array}$ & $\begin{array}{l}Q_{2} \\
\text { Self-sufficient, } \\
\text { Resourceful }\end{array}$ & $\begin{array}{l}Q_{3} \\
\text { Controlled, } \\
\text { Disciplined }\end{array}$ & AGE & CREATIVITY \\
\hline \hline Talent & .37 & .26 & .26 & .46 & .21 \\
& $P .002$ & $P .002$ & $P .024$ & $P .000$ & $P .049$ \\
\hline
\end{tabular}




\section{DISCUSSION}

The hypothesized relationship between talent and extroversion was not supported. The hypothesized relationship between talent and personality was partially supported. Ancillary findings support the talent/personality position.

The personality profiles of the talented musician, the pre-professional musician, and the non-talented can be differentiated, but the differences, with two exceptions, do not reach statistical significance (Figure 1.). The first parameter that yielded significance was conscientiousness. The positive linear relationship between musical talent and conscientiousness indicates that musical accomplishment is a partial function of a desire to perform. That university music majors may be differentiated from professional performing musicians suggests a quantitative, not qualitative difference. The competitive demands of professional musicianship probably necessitates greater commitment on the part of a musician.

The second parameter that obtained significance was age. A positive linear relationship across groups indicates that the longer one's experience as a performing musician, the greater one's proficiency at performance. In this particular instance, however, the relationship between talent and age may be more apparent than real. The pre-professional group was composed entirely of university students ranging in age from 20-28. The high talent or professional group ranged in age from 26-65. There could conceivably be members in the university group as talented, or more talented, than their older professional counterparts. 
Cattell (1970) provides a profile of 23 musical performers and 31 musicians who subsequently became music therapists. As Shatin, et al (1968) indicates, the performers are more surgent $(F)$ enthusiastic, more protensive (I) sensitive, with greater autia (M) imaginativeness, and radicalism (Q). This suggests a strong subjectivity and a refusal to accommodate. There is, additionally, self-discipline and self-reliance in the high self-sentiment $\left(Q_{3}\right)$, super ego $(G)$, and self-sufficiency $\left(Q_{2}\right)$. 
Graphic Representation of Personality Profiles

\section{Legend:}

Low Talent

$\mathrm{HHHH}$

Pre-professional

High Talent

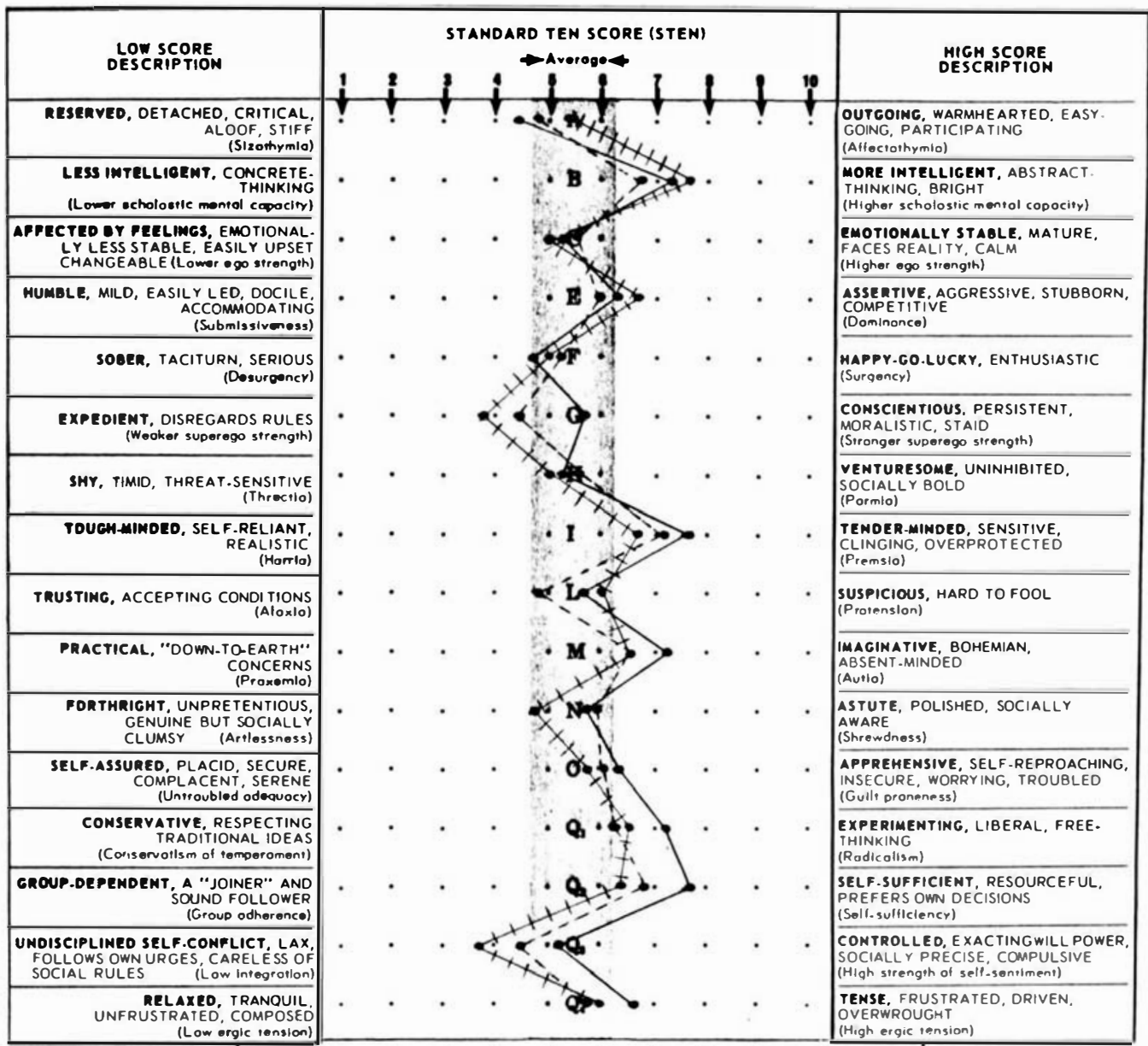

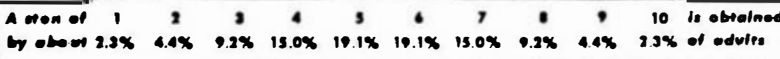

Figure 1. 
The results of the present study, in general, support Cattell's (1970) findings. Positive linear relationships (non-significant trends) were found to be congruent with Cattell's profile for 13 of the 16 personality factors studied. The three factors not in agreement with Cattell's were: 1) enthusiastic, 2) suspicious, and 3) radicalism. In each instance, a curvilinear relationship was observed. This variation is perhaps attributable to a differential effect for age, operative in both the low and high talent groups. Both the low and high talent groups were more heterogeneous with respect to age than the pre-professional group.

Ancillary data (Table 1.) provided five factors which were shown to be significantly related to musical talent. Two of these, age and conscientious/ persevering have been discussed. Self-sufficiency/Resourceful and Disciplined/ following Self-image, both indicate a self-determining inner directed individual. The extent to which these factors can be used to differentiate between the low talent, pre-professional, and high talent group did not reach significance, however.

Creativity, although a component of musical talent, is clearly not, as has been discussed (Child, 1969), identical to talent. This finding suggests that there are factors specific to success within the musical idiom, and not a general creative or artistic factor responsible for all artistic accomplishment.

Factor analysis yielded second order dimensions: 1) Anxiety, 2) Independence, 3) Exvia, 4) Perseverance, and 5) a factor for Analytical/ Creativeness. Perseverance was found to load substantially on talent. The 
other factor loadings were not of a substantial nature. The emergence of perseverance as an important correlary of musical talent suggests that success as a performing musician is dependent upon recognition as a performer, and recognition is a partial function of one's willingness to perform until recognition is achieved. Conceivably, the greatest potential talent could go unnoticed both by their possessor and by others, if persistent expression of the ability were not made.

In view of these considerations, the following profile of the talented musician emerges, Figure 1.

He or she is a person somewhat detached and critical, a person less outgoing than most. The talented musician is a person of better than average intelligence; he or she is able to think abstractly. The talented musician is emotionally stable, faces reality calmly, and is not at the mercy of his or her feelings. He or she is more competitive and assertive than most people. The musician is more sober and taciturn than most people. He or she is venturesome, yet sensitive; self-opinionated and imaginative. The talented musician is moderately astute and genuine. He or she is more insecure and apprehensive than most. The musician is free thinking - likes to experiment. He or she is not a "joiner," but prefers to rely upon his or her own resources and decisions. The talented musician is disciplined and evidences greater willpower than most people. Finally, the talented musician is somewhat more tense and driven than most people. He or she maintains a higher level of frustration, and is less relaxed than most people in the general population. 
This study made two specific predictions: 1) that extroverts, individuals demonstrating factor elevations on Cattell's factor Exvia, would be more likely to be found among the talented than the low talent group, and 2) that musically talented individuals could be differentiated from untalented individuals with respect to personality. In the former case, no support was found; in the latter, partial support was found.

That the talented musician tends to be introverted rather than extroverted clarifies a conceptual issue and assumption made in the research proposal. It was originally assumed that when performing, the musician's involvement with the music and instrument provided an external mode of expression, a communication of sorts, with an audience tantamount to inter-personal interaction. The data suggests that this is not the case. It appears that involvement with a musical instrument is, nevertheless, involvement with a thing and ideas, and as such is no substitute for inter-personal interaction. Metaphors aside, the living, transforming qualities of a musical performance are no substitute for face to face human interaction.

Finally, regarding the differentiation of talented and untalented individuals, with respect to personality, considerable caution is necessary. There are few parameters on which musically talented and non-talented individuals are diametrically opposed. Instead, it appears that non-talented and musically talented individuals share numerous personality characteristics. The differences that do exist, however, appear to be ones of degree rather than kind. Additional data and the establishment of personality norms for talented musicians may help to clarify the significance of these slight differences, and provide an auxiliary means of identifying the talented musician. 
LIST OF REFERENCES 


\section{LIST OF REFERENCES}

Anastasi, A. Psychological testing, revised edition. New York: The Macmillan Company, 1961.

Bakan, P. Extraversion-introversion and improvement in an auditory vigilance task. British Journal of Psychology, 1959, 50, 325-332.

Barth, G.W. "Some Personality and Temperament Characteristics of Selected School Music Teachers." Ed.D. dissertation, University of Southern California, 1961.

Bentley, A. Music ability in children and its measurement. London: George G. Harrap and Company, Lt d., 1966, p. 13.

Cattell, R.B. Personality: A systematic theoretical and factual study. New York: McGraw-Hi 11, 1950.

Cattell, R.B., Eber, A.W., Tatsuoka, M.M. Handbook for the Sixteen Personality Factor Questionnaire (16PF), 1970 Edition, Institute for Personality and Ability Testing, Champaign, Illinois.

Child, I.L. Esthetics. In The Handbook of Social Psychology, Volume III. Addison Wesley Publishing Company, 1969, $\overline{8} 5 \overline{3-909 .}$

Cooley, J.C. "A Study of the Relation Between Rating of Musical Ability." Journal of Research in Music Education, 1961.

Drake, R.M. Factorial analysis of music tests by the Spearman tetraddifference technique. Journal of Musicology, 1939, $1,6-16$.

Eysenck, H.J. Personality and extra-sensory perception. Journal of the Society for Psychical Research, 1967, 44, 55-71.

Farnsworth, P.R. An historical, critical and experimental study of the Seashore-Kwalwasser Test Battery. Genetic Psychology Monographs, 1931, $\underline{9}$, 291-393.

Farnsworth, P.R. The Kwalwasser-Dykema tests as psychological tools. Genetic Psychology Monographs, 1934, 15, 50-84.

Freud, S. A general introduction to psychoanalysis. New York: Washington Square Press, $19 \overline{5} 2$.

Gardner, C.E. Characteristics of outstanding high school musicians. Journal of Research in Music Education, 1955, $\underline{3}$. 
Gordon, E. Iowa tests of music literacy. Iowa City: Bureau of Educational Research and Service, University of Iowa, 1971.

Haecker - Th.Ziehen. Zur Vererbung and Entwicklung der Musikalischen Begabund, 1922.

Heymans - E. Wiersma. Beitraege zur Speziellen Psychologie auf Grund einer Massenuntersuchung, Ges. Kleinere Schriflen, III.

Kwalwasser, J., \& Dykema, P.W. Kwalwasser-Dykema music tests. New York: Fischer, 1930.

Lundin, R.W. The objective psychology of music. New York: The Ronald Press Company, 1967.

Mcdouga 11, W. The chemical theory of temperament applied to introversion and extroversion. Journal of Abnormal and Social Psychology, 1929, 24, 293-309.

McLeish. The validation of Seashore's Measures of Musical Talents by factorial methods. British Journal of Psychology (statistical section), $1950, \underline{3}, 129-140$. $435-452$.

Murray, H.A. In nomine diabolu. New England Quarterly, 1951, 24,

Mursel1, J.L. The psychology of music. New York: W. N. Norton and Company, Inc., 1937, p. 300. 1924.

Ogden, R.M. Hearing. New York: Harcourt, Brace and Company, Inc., (unpublished).

Peters, W. Die Vererbung Geistiger Eigenschaften. Jena, 1925.

Rainbow, E.L. A pilot study to investigate the constructs of musical aptitude. Journal of Research in Mus ic Education, 1965, 13, 3-14.

Revesz, G. Introduction to the Psychology of Music. University of Oklahoma Press, 1954.

Rosenzweig, S. The ghost of Henry James: A study in thematic apperception. Character and Personality, 1943, 12, 79-100.

Seashore, C.E. The psychology of musical talent. New York: Silver Burdett Company, 1919, pp. 14-15. 
Seashore, C.E. Psychology of music. New York: McGraw-Hill Book Company, 1938, p. 332 .

Scheinfeld, A. Your heredity and environment. Philadelphia: J.B. Lippincott Company, $1 \overline{965 .}$

Schoen, M. The validity of tests of musical talent. Journal of

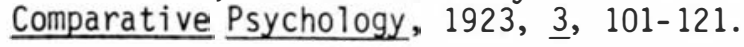

Schoen, M. Tests of musical feeling and musical understanding. Journal of Comparative Psychology, $1925, \underline{5}, 31-52$.

Schoen, M. The psychology of music. New York: The Ronald Press Company, 1940 , p. $\overline{151}$.

Schleuter, S.L. An investigation of the interrelation of personality traits, musical aptitudes and musical achievement. Studies in the Psychology of Music, Ph.D. dissertation, University of Iowa, 1971.

Shatin, L., Kotter, W., and Douglas-Longmore, G. Personality of Successful Music Therapists. Journal of Music Therapy, 1968, 5, 4, 111-113.

Smith, S.L. Extroversion and sensory threshold. Psychophysiology, $1968, \underline{5}, 293-299$.

Stanton, H.M. Measurement of musical talent: The Eastman experiment. University of Iowa Studies, 1935, Number 291, 1-140.

Thayer, R.W. The interrelation of personality traits, musical achievement and different measures of musical aptitude. Research in the Psychology of Music, University of Iowa Press, 1972.

Trilling, L. The Liberal Imagination. The Viking Press, Inc., 1949.

Wing, H.D. A factorial study of musical tests. British Journal of Psychology, 1941, 31, 341-355. 
APPENDIX 


\section{APPENDIX 1}

Questions used for the selection of participants in the low talent group:

1. Would you describe yourself as a person possessing music ability?

2. Do you dislike music?

3. Would you describe yourself as someone who "can't carry a tune in a bucket?"

4. How do you know you have no musical ability?

In order for prospective subjects to be included in the low talent group, all questions had to be answered in the following manner: Questions 1. and 2. required an answer No, Question 3. required an answer of Yes, Question 4. required an answer on the order of "When I was a child I took mus ic lessions for a year. It was a waste of time. I didn't get anywhere with it."

An answer like, "I don't know if I have any musical ability; I've never tried to play an instrument," disqualified the prospective subject from inclusion in the low talent group. 
VITA

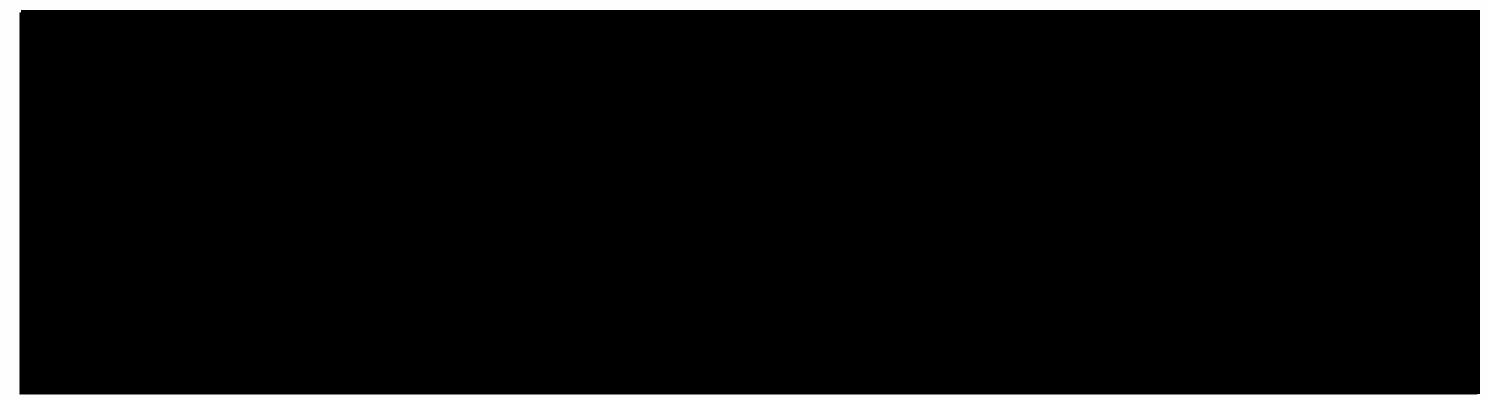

